\title{
DIAGNÓSTICO DO ARRANJO PRODUTIVO LOCAL DE CONFECÇÃO DE CATALÃO: O CASO EXECUTADO POR UMA ORGANIZAÇÃO SOCIAL
}

\author{
José Querino Tavares Neto* \\ Daniella Paula de Freitas**
}

Resumo: Este artigo tem como objetivo traçar o perfil do APL de Confecção do município de Catalão, suas demandas e carências para implantação de ações de Desenvolvimento Tecnológico no mesmo. A pesquisa seguiu o método censitário, mapeando a totalidade do universo proposto para análise, por meio da ferramenta digital de aplicação Hash Data. Apenas 22 foram encontradas. Observou-se como resultados da pesquisa, carências no campo da gestão das empresas e uma forte desarticulação do APL. Com base no diagnóstico, foram apontadas sugestões de fortalecimento do APL, por meio das quais, várias políticas públicas foram elaboradas.

Palavras-chave: Políticas Públicas; Organizações Sociais; Publicização; Arranjos Produtivos Locais; Inovação.

\section{DIAGNOSIS OF THE LOCAL PRODUCTION ARRANGEMENT OF CATALÃO CONFECTION: THE CASE EXECUTED BY A SOCIAL ORGANIZATION}

\begin{abstract}
This article aims to outline the profile of APL de Confecção of the municipality of Catalão, its demands and needs for the implementation of Technological Development actions in it. The research followed the census method, mapping the totality of the universe proposed for analysis, through the digital tool of application Hash Data. Only 22 were found. The results of the research, lack in the field of business management and a strong disarticulation of the APL were observed as results of the research. Based on the diagnosis, suggestions were made for strengthening the APL, through which several public policies were elaborated.
\end{abstract}

Keywords: Public policy; Social Organizations; Publication; Local Productive Arrangements; Innovation.

\footnotetext{
* Professor Associado da Faculdade de Direito da Universidade Federal de Goiás e Pontifícia Universidade Católica de Goiás. Professor do Programa de Mestrado em Políticas Públicas da UFG. Pós-doutor em Direito Constitucional pela Universidade de Coimbra com bolsa da Capes. Consultor das Faculdades Atenas de Paracatu. Bolsista de Produtividade do Programa de Pós-Graduação em Direito e Políticas Públicas da UFG. josequerinotavares@gmail.com.

** Professora e Coordenadora da Empresa Júnior da Universidade Estadual de Goiás, Câmpus Caldas Novas e Aparecida de Goiânia. Consultora de Gestão na Kasulo Consultoria. MBA em Logística de Produção e Distribuição pelo IPOG. adm.daniellafreitas@gmail.com.
}

Rev. de Direito, Inovação, Propriedade Intelectual e Concorrência| e-ISSN: 2526-0014 | Porto Alegre | v. 4 | n. 2 |p. 96-113| Jul/Dez. 2018 


\section{INTRODUÇÃO}

A Constituição de 1988 trouxe mudanças na forma de agir e pensar do Estado. O foco passou a ser nas questões sociais, nos direitos de cidadania e na livre associação, bem como na descentralização da competência do Estado, permitindo a legitimação do terceiro setor. O que veio se consolidar no Plano diretor da reforma do aparelho de Estado (BRASIL, 1995, p.10). O Plano Diretor buscou reverter a gradual deterioração dos serviços públicos, definindo objetivos e diretrizes para a reforma da administração pública. Buscando implantar uma administração pública "gerencial, baseada em conceitos atuais de administração e eficiência, voltada para o controle dos resultados e descentralizada para poder chegar ao cidadão", dando ênfase na produtividade do serviço público.

No Plano Diretor foi definida a gestão compartilhada, onde o Estado passa às Organizações Sociais (OS) a gestão dos serviços não-exclusivos do Estado, permitindo a descentralização dos mesmos, entendendo que os serviços serão mais eficientemente realizados pelas Organizações Sociais, por meio do financiamento do estado. Desta forma, o poder executivo concede autorização legislativa para a celebração dos contratos (BRASIL, 1995), cabendo às OS, com autonomia financeira e administrativa, gerir os recursos de forma eficiente, batendo as metas e indicadores definidos no contrato de gestão, em contrapartida o Estado realiza repasses monetários para subsidiar o trabalho das mesmas. Este novo modelo de gestão compartilhada prevê as seguintes vantagens:

(...)assimilar características de gestão cada vez mais próximas das
praticadas no setor privado, o que deverá representar, entre outras
vantagens: a contratação de pessoal nas condições de mercado; a
adoção de normas próprias para compras e contratos; e ampla
flexibilidade na execução do seu orçamento (BRASIL, 1997, p.14).

Tais vantagens pretende permitir maior flexibilidade e agilidade nas ações e melhor atendimento das demandas da sociedade, resolvendo o problema da burocracia do Estado e da morosidade nos processos internos. O novo modelo de gestão, Estado e OS, está em execução em diversas regiões do país. Em Goiás a participação das OS se dá, principalmente, no ramo da saúde, educação profissional tecnológica e desenvolvimento tecnológico, sendo os dois últimos ramos, objetos foco deste projeto de pesquisa. De acordo com a SED (2017) o Governo de Goiás repassou a gestão da educação profissional e do desenvolvimento tecnológico do estado para cinco OS, abrangendo também a gestão da Rede ITEGO (Instituto Tecnológico do Estado de Goiás), ou seja, constituiu uma política de governo. 
A pesquisa ocorreu como parte das atribuições destinadas à OS Instituto Reger pelo edital de chamamento público $\mathrm{n}^{\circ}$ 007/2016-SED. O Instituto Reger é responsável pela regional 3 que compreende 30 municípios goianos, 4 ITEGOs, 7 COTECs e vários Arranjos Produtivos Locais (APL). Entre eles encontra-se o APL de Confecção, objeto deste trabalho, situado na cidade de Catalão. A pesquisa foi realizada com o objetivo de traçar o perfil do APL de Confecção do município, levantar suas demandas e carências para que sejam implantadas ações de Desenvolvimento Tecnológico no mesmo.

A pesquisa bibliográfica estabeleceu como teleologia e paradigma os conceitos Políticas Públicas, Plano diretor da reforma do aparelho de Estado, Terceiro Setor, Organizações Sociais, Contrato de Gestão, entre outros; e, numa acepção procedimental, utilizou-se o a técnica censitária, a fim de compreender a realidade econômica do APL de Catalão.

\section{POLÍTICA PÚBLICA E GESTÃo COMPARTILHADA EM GOIÁS}

Para fins deste artigo, adota-se o termo Política como atividade de conhecimento e organização do poder. Já em relação ao termo Políticas Públicas cabe abordar o viés político, envolvendo processos decisórios e conflito de interesse, e o viés administrativo, definido por Bucci (2002) como programas de ação governamental, tanto em instância federal, quanto estadual ou municipal, que tem como finalidade coordenar os recursos à disposição do Estado, bem como as atividades privadas para um fim específico e que atenda objetivos sociais relevantes. Ambos vieses da Política Pública visam assegurar determinados direitos de cidadania para vários grupos da sociedade ou para determinados segmentos.

Tais Políticas Públicas ainda podem ser divididas em Política de Estado, que independe de quem está no governo e é garantida pela Constituição Federal, e Política de Governo, que é definida pelo governo eleito que tem a oportunidade de criar seu próprio planejamento. Cabe ressaltar que boas Políticas de Governo podem ter continuidade de um governo para outro e podem ser transformadas em Políticas de Estado. As Políticas Públicas, sejam elas Políticas de Estado ou Políticas de Governo, é um assunto muito discutido na atualidade. O conceito do 'Público' deixou de ser um sinônimo de gestão governamental e nos dias atuais é entendido muito mais como um sinônimo de interesse público, que vai do governo até a sociedade, passando por diversas organizações da sociedade civil. 
As Políticas Públicas, hoje, vão envolver o primeiro, segundo e o terceiro setor. No primeiro setor se encontra o Estado, com a responsabilidade de defender o interesse do povo. No segundo setor se encontram as empresas, conhecido também como o setor privado ou de mercado. E no terceiro setor encontram-se as associações e fundações com um "conjunto de iniciativas privadas, de caráter público, sem fins econômicos" destinadas a atender o interesse público (TAVARES NETO; FERNANDES, 2010, p. 373). Dentre as organizações pertencentes ao terceiro setor podemos citar as organizações não governamentais, Organização da Sociedade Civil de Interesse Público (OSCIP), fundações, entidades filantrópicas, associações de bairro, movimentos sociais, entre outros.

A relação da Políticas Públicas com o terceiro setor, tornou-se mais forte após o Plano diretor da reforma do aparelho de Estado, criado em 1995, também conhecido como Reforma Gerencial, elaborado pelo Ministério da Administração Federal e da Reforma do Estado, na pessoa do ministro Bresser Pereira, submetido e aprovado pelo Presidente da República, na época Fernando Henrique Cardoso (BRASIL, 1995). A reforma significou a introdução da cultura e das técnicas modernas (da Administração privada) na Administração pública. Com o intuito principal de diminuir o custo da Administração Pública, aumentar a qualidade e a eficiência dos serviços prestados. Para tanto

(...) a reforma gerencial (1) torna os gerentes dos serviços responsáveis
por resultados, ao invés de obrigados a seguir regulamentos rígidos; (2)
premia os servidores por bons resultados e os pune pelos maus; (3)
realiza serviços que envolvem poder de Estado por meio de agências
executivas e reguladoras; e - o que é mais importante - (4) mantém
gratuitos os grandes serviços de consumo coletivo, mas transfere sua
oferta para organizações sociais, ou seja, para provedores públicos não
estatais que recebem recursos do Estado e são controlados por meio de
contrato de gestão. Através dessas quatro características -
principalmente da última - o poder público garante os direitos sociais,
mas transfere sua provisão ou oferta para organizações quase-estatais
que são as organizações sociais. (BRESSER-PEREIRA, 2017, p.153)

A partir do Plano diretor da reforma do aparelho de Estado de 1995, a Administração Pública passou a ser gerida de uma forma diferente. Passou-se a ter definições claras dos objetivos a serem alcançados, a gestão ficou mais descentralizada, com mais autonomia aos seus gerentes. A avaliação passou a ser nos resultados finais, os cidadãos a serem enxergados como usuários dos serviços públicos e a cultura e técnicas da administração privada a ser inseridas na Administração Pública, assim como a transferência da gestão dos serviços nãoexclusivos do Estado às Organizações Sociais, pertencentes ao terceiro setor. Na transferência 
de atividades não-exclusivas, segundo Brasil (1995, p.74), “os hospitais, as universidades e escolas técnicas, os centros de pesquisas, as bibliotecas e os museus" são priorizados.

Fernandes (1994, p. 21) define o terceiro setor como “(...) um conjunto de organizações e iniciativas privadas que visão à produção de bens e serviços públicos”. As organizações precisam, para se enquadrar no terceiro setor, possuir uma realidade institucional, não ter fins lucrativos, ser institucionalmente separada do governo e controlar suas próprias atividades. Podem promover benefícios coletivos privados, beneficiando um grupo restrito de pessoas ou promover benefícios de caráter público, focando nos interesses mais comum da sociedade. Também podem atender em áreas distintas, definidas em suas missões, objetivos e funções:

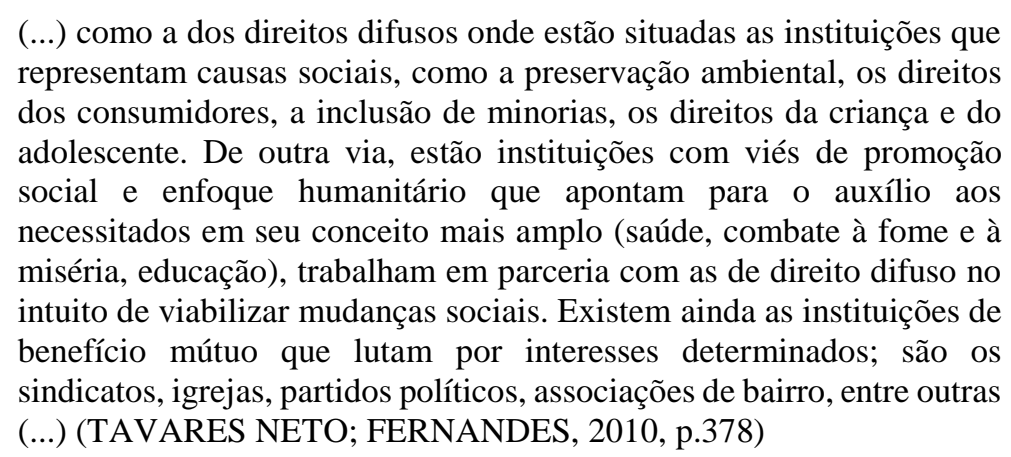

As áreas de atuação do terceiro setor são vastas, vão desde a preservação ambiental, muito frequente na Amazônia Brasileira; também a inclusão de minorias, como é o caso das instituições que lutam pelo direito dos negros ou grupos indígenas; bem como as atuações sindicais, que buscam consolidar o direito dos trabalhadores. Tavares Neto e Fernandes (2010) ainda apontam um outro tipo de atuação, a de apoio às instituições de todas as áreas, seja o apoio financeiro, gerencial, técnico, ideológico ou institucional, por meio de serviços e pesquisas.

As organizações sociais são entidades privadas, sem fins lucrativos, participantes do terceiro setor, que celebram um contrato de parceria com o Estado, criando assim um vínculo específico com o mesmo. Ou seja, as OS são formadas por meio da celebração do termo de parceria (contrato de gestão). Tal contrato traz consigo benefícios e responsabilidades. Como benefícios estatais recebidos encontram-se o fomento em dinheiro para a realização das atividades contratadas, a seção de bens e a seção de servidores públicos, com ônus para a origem, o governo. Em contrapartida, as OS se submetem ao controle direto da Administração Pública, tanto por meio de servidores públicos integrando o conselho de Administração da própria OS, como requisito obrigatório, como no controle exercido pelo tribunal de contas sobre as mesmas.

Rev. de Direito, Inovação, Propriedade Intelectual e Concorrência| e-ISSN: 2526-0014 | Porto Alegre | v. 4 | n. 2 |p. 96-113| Jul/Dez. 2018 
Para que o contrato de parceria seja celebrado, há todo um processo de implementação, conhecido como publicização. De acordo com Brasil (1997, p.17) “publicização refere-se à produção não-estatal de bens públicos, por entidades situadas no âmbito do denominado terceiro setor (setor de serviços não orientado para o lucro)". Para a implementação da OS é necessário extinguir as entidades estatais que executavam os serviços públicos, e transferir tal execução para entidades qualificadas como OS, utilizando para isso, o contrato de gestão. Neste caso, as entidades estatais não se transformam ou são convertidas em OS, elas deixam de existir, se tornam não entidades, ou seja, são publicizadas.

O processo de Publicização é mostrado na figura 1. A primeira etapa é composta por: a) ações de implementação, que abrange a decisão do Governo em disponibilizar determinados serviços para o modelo de gestão compartilhada, incluindo a divulgação e o protocolo de intenções. b) ações prévias, abrangendo a preparação da organização estatal, a criação da OS (organização não-estatal) e a preparação do contrato de gestão que vai direcionar todo o trabalho da Organização Social. c) atos legais, composto pela extinção da entidade estatal e a qualificação da OS. d) ações posteriores é o último item da primeira etapa e engloba o inventário simplificado da organização estatal que está sendo extinta, a absorção da atividade pela OS, via assinatura do contrato de gestão e a negociação do mesmo contrato.

Figura 1 - Processo de Implementação das Organizações Sociais

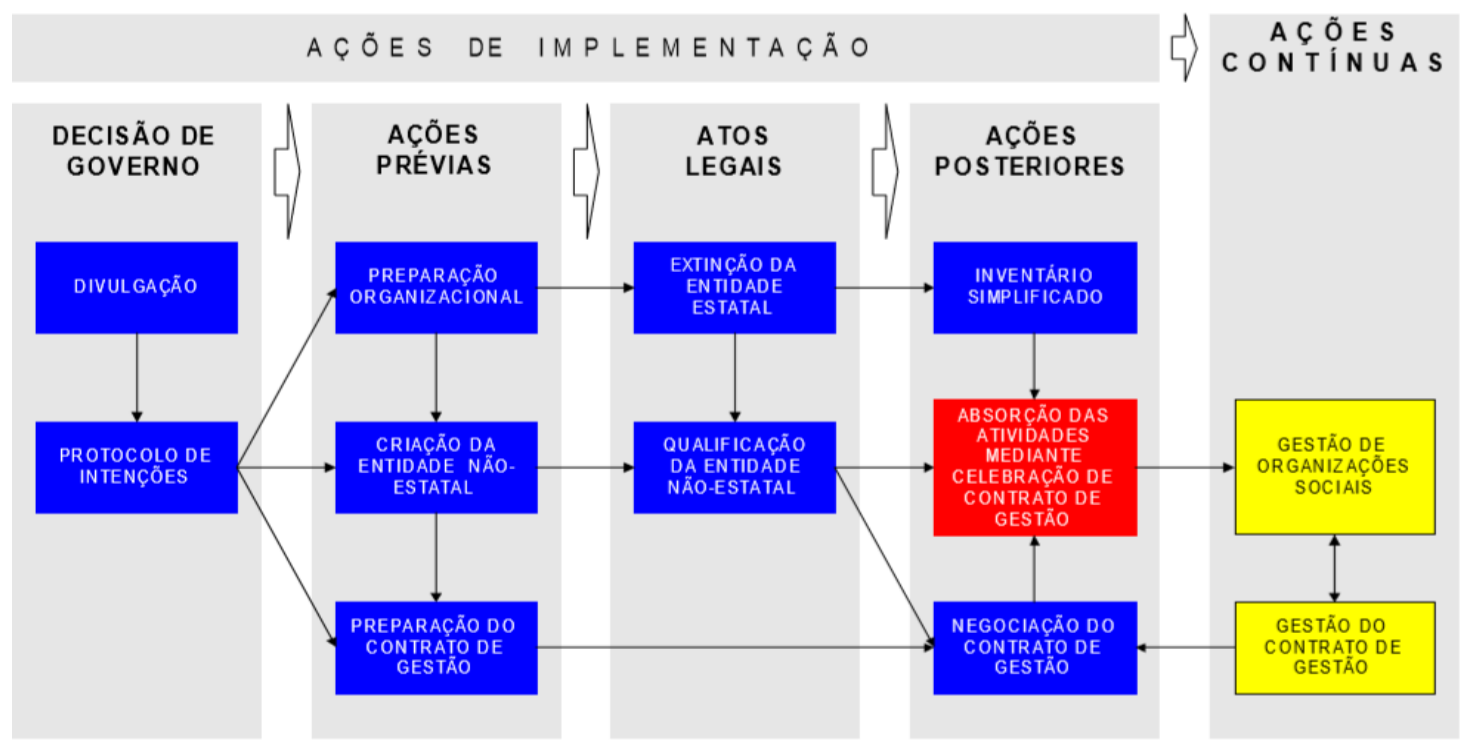

Fonte: (BRASIL, 1997, p.18). 
A segunda etapa do processo de implementação das OSs abrange a gestão de organizações sociais que precisa ter o foco no cidadão, a ênfase em resultados, o controle social e flexibilidade. O outro item da segunda etapa é a gestão do contrato que inclui relatórios de avaliação, acompanhamento e ações corretivas. $\mathrm{O}$ acompanhamento ocorre de forma contínua e inclui cumprimento de metas e indicadores, acompanhada de perto pela SED.

Na primeira etapa do processo de publicização (Ações de Implementação) acontece a qualificação da entidade não estatal em organização social. Para regulamentar essa qualificação no Estado de Goiás, no dia 28 de dezembro de 2005, foi decretada e sancionada a Lei Estadual $\mathrm{n}^{\mathrm{o}}$ 15.503. Na referida lei, o Chefe do Executivo fica responsável por qualificar as OS, o que pode acontecer a qualquer tempo, desde que seja dentro de 15 dias corridos anteriores à data da avaliação de capacidade técnica para a área em que a entidade pretende se qualificar. A lei também versa sobre a responsabilidade do Poder Público em estimular a qualificação do maior número possível de entidades para que aconteça uma concorrência justa.

Para que a entidade seja qualificada como OS, a mesma precisa comprovar o registro de seu ato constitutivo, não ser qualificada pelo Estado de Goiás como organização da sociedade civil de interesse público e atuar essencialmente nas seguinte áreas: assistência social, cultura, educação, desenvolvimento tecnológico, gestão de atendimento ao público, gestão de serviços sociais e auxiliares em unidades prisionais, integração social do menor infrator e garantia de seus direitos individuais e sociais, pesquisa científica, proteção e preservação do meio ambiente, saúde, educação profissional e tecnológica, esporte e lazer, assistência técnica e extensão rural (GOIÁS, 2006).

Após a qualificação das OS é realizado o chamamento público para a celebração do contrato de gestão. O chamamento público contempla a publicação do edital que deve conter os seguintes itens: a) descrição detalhada da atividade a ser executada e dos bens, recursos e equipamentos a serem destinados ao fim pretendido; b) critérios objetivos para seleção da proposta no que se refere à eficiência técnica, operacional e de gestão; c) exigências relacionadas com a comprovação de regularidade jurídica e fiscal; d) o prazo para a apresentação da proposta, que deve ser de, no mínimo, 30 dias após a publicação do edital.

Sendo a OS selecionada para a celebração do contrato de gestão, a entidade passa a ser fiscalizada pelo Tribunal de Contas do Estado de Goiás. A fiscalização envolve, segundo Goiás (2017), inspeções, auditorias e acompanhamento, tanto com relação à qualificação da OS, quanto da formalização e da execução do contrato de gestão. Em relação à fiscalização da 
execução do contrato, são realizadas avaliações periódicas (trimestrais), servindo para apontar possíveis desvios e adequações necessárias para obtenção de melhores resultados, e avalições anuais, para mensurar o real desempenho da OS e o alcance das metas definidas no contrato de gestão.

O Estado de Goiás, em 2016, por meio da Secretaria de Estado de Desenvolvimento Econômico, Científico e Tecnológico e de Agricultura, Pecuária e Irrigação (SED), tornou público cinco Instrumentos de Chamamento para a seleção de Organizações Sociais, qualificada em educação profissional tecnológica e desenvolvimento tecnológico no âmbito do Estado de Goiás, para celebração de Contrato de Gestão objetivando transferir a administração e operacionalização de equipamentos públicos da Rede Pública Estadual de Educação Profissional (Rede ITEGO) visando a oferta de educação profissional e ações de desenvolvimento e inovação tecnológica (SED, 2016).

Para que a gestão compartilhada, no âmbito educação profissional tecnológica e desenvolvimento tecnológico, fosse possível, o Estado de Goiás foi dividido em cinco regionais. Regional 1 abrangendo os ITEGOs de Cristalina, Niquelândia, Porangatu, Santo Antônio do Descoberto e Valparaíso. Regional 2 abrangendo os ITEGOs de Caiapônia, Ceres, Goianésia, Piranhas e Uruana. Regional 3 com os ITEGOs de Anápolis e Catalão. Regional 4 com os ITEGOs de Goiânia, Cidade de Goiás, Goiatuba e Piracanjuba. Por fim, regional 4 abrangendo os ITEGOs de Aparecida de Goiânia, Goiânia, Mineiros e Santa Helena de Goiás.

Por ter sido usada a estratégia de dividir o Estado de Goiás em cinco regionais, foi necessário fazer cinco Chamamentos Públicos e consequentemente, cinco Contratos de Gestão. As OS selecionadas para celebrar os contratos com o Governo do Estado foram: Ibracedes (Regional 1), Faespe (Regional 2), Reger (Regional 3), Cegecon (Regiona 4) e Centeduc (Regional 5).

Coube a cada OS selecionada, a operacionalização das ações de educação profissional, incluindo atividades de ensino, pesquisa e extensão, por meio de cursos e programas de formação inicial continuada ou qualificação profissional, educação profissional técnica de nível médio e educação profissional tecnológica de graduação e pós-graduação, nas modalidades presencial e a distância. Bem como a operacionalização das ações de desenvolvimento e inovação tecnológica (DIT), por meio de atividades de transferência de tecnologia, prestação de serviços tecnológicos e promoção e fortalecimento de ambientes de inovação, bem como as atividades de apoio auxiliares ao setor produtivo. 
A SED (2016) define atividades de transferência de tecnologias como a transferência de conhecimento, habilidades e procedimentos aplicáveis aos problemas da produção de empresas do setor produtivo da região, desde que amplie a capacidade de inovação da organização receptora. Prestação de serviços tecnológicos como o oferecimento de ensaios, testes e certificações ao setor produtivo de vocação da região onde os ITEGOs estão inseridos. Também define a promoção e fortalecimento de ambientes de inovação como implantação de processos de incubação de negócios, seja incubadora de empresas ou arranjos produtivos locais (APL). Sendo a promoção e fortalecimento de ambientes de inovação aplicados também aos alunos e à comunidade.

Para os efeitos deste Decreto, consideram-se Arranjos Produtivos Locais os aglomerados de agentes econômicos, políticos e sociais, localizados em um mesmo espaço territorial, que apresentem, real ou potencialmente, vínculos consistentes de articulação, interação, cooperação e aprendizagem para a inovação tecnológica (Goiás, 2004)

De acordo com o Decreto 5.990 de 12 de agosto de 2004, citado acima, entende-se arranjos produtivos locais (APL) como aglomerações de empresas do mesmo segmento produtivo, localizadas no mesmo território, possuindo vínculo de articulação, interação, cooperação e aprendizagem entre si. Contando com o apoio do Governo, instituições de crédito, ensino e pesquisa. Os APL são classificados como articulados, não articulados e em articulação. Dentre os APL articulados em Goiás, podemos citar o de Açafrão de Mara Rosa, de Calçados em Goiânia e Goianira, Confecções de Catalão, da Cachaça que abrange quase todo o Estado, Cerâmica Vermelha do norte goiano, Mandioca e derivados de Iporá, Lácteo da Estrada de Ferro, entre outros.

Participar de um APL fortalece as empresas, pois juntas formam um grupo articulado e importante para a sua região, facilitando a interação com o governo, associações empresariais, associações de produtores, órgãos públicos, instituições de crédito de ensino e de pesquisa. Além disso, torna os participantes mais articulados, trabalhando de forma cooperativa e trocando informações entre si, gerando melhorias e novas ideias entre todos.

O APL de Confecção de Catalão iniciou seu processo de formalização em 2016 e tem como base a União das Indústrias de Confecção de Catalão e do Sudoeste Goiano (UNICON), fundada em 27 de abril de 2001. Hoje, este APL faz parte da zona de influência da Região 03 (Contrato de Gestão nº 01/2017/SED, formalizado em 10 de abril de 2017) e consta nas dimensões de ação do “EDITAL - CHAMAMENTO PÚBLICO Nº 007/2016-SED - Processo 
n 201614304000689 - Lote no 3", da Secretaria de Estado de Desenvolvimento Econômico, Científico e Tecnológico e de Agricultura, Pecuária e Irrigação - SED”.

\section{RESULTADOS DA PESQUISA}

A pesquisa seguiu o método censitário, tentando mapear a totalidade do universo proposto. Para tanto, realizou-se da pesquisa de campo, com a utilização do instrumento estruturado (questionário) aplicado mediante a ferramenta digital Hash Data, que também foi utilizada para o tratamento dos dados. Em 18/04/2016, ainda no processo de formalização do APL, constavam da UNICON (associação de confecções formadora do APL) 46 empresas. Em abril de 2018, segundo foi levantado com a Secretaria de Estado de Desenvolvimento (SED), o APL era formado por 35 empresas. Após o levantamento e mapeamento georreferenciado, levantou-se a seguinte situação:

Quadro 1 - Levantamento das empresas pertencentes ao APL de Confecção

\begin{tabular}{|l|r|}
\hline Encontradas/pesquisadas & $60 \%$ \\
\hline Mudou para Goiânia & $3 \%$ \\
\hline Não está fabricando, somente loja & $6 \%$ \\
\hline Não tem interesse no APL & $6 \%$ \\
\hline Proprietária não encontrada & $8 \%$ \\
\hline Não pôde receber os pesquisadores & $3 \%$ \\
\hline Empresa não encontrada & $14 \%$ \\
\hline
\end{tabular}

Fonte: elaborado pela equipe de pesquisa.

Conforme demonstrado no quadro $1,40 \%$ do universo censitário não respondeu à pesquisa por motivos diversos: mudança para Goiânia (3\%); encerro a fabricação de roupas mas manteve a loja e, neste momento, compra de outras confecções (6\%); não demonstra interesse pelo APL e, por isso, preferiu não receber os pesquisadores (6\%); a proprietária seria a única que poderia responder à pesquisa e, após insistentes tentativas, afirmou não poder atender os pesquisadores (8\%); simplesmente justificou não possuir agenda para receber os pesquisadores nos dois dias em que estiveram em campo (3\%); do total investigado, parte das empresas (14\%) não foram encontradas, podendo significar que estão com as atividades paralisadas ou que mudaram de endereço e telefone.

A equipe foi a campo por dois dias (16 e 17 de maio), com duas equipes no primeiro dia e três no segundo dia, procurando sempre retornar aos endereços que não foram 
encontrados, procurando informações sobre as empresas junto à comunidade local, ver locais na figura 2. Além da aplicação de questionário, os proprietários das confecções foram entrevistados discursivamente tendo em vista captar as sensações subjetivas dos mesmos acerca da cidade, seus problemas e soluções. O resultado será evidenciado a seguir.

Figura 2 - Locais visitados

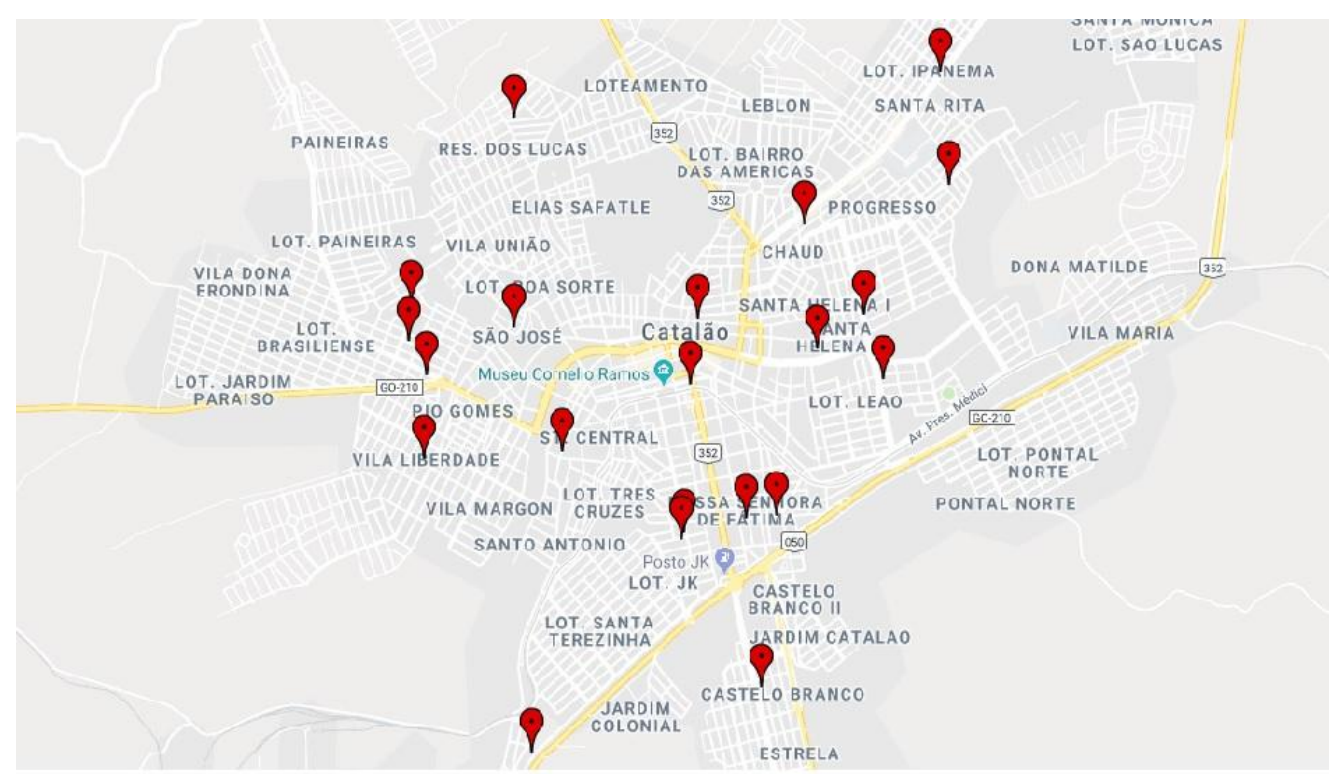

Fonte: elaborado pela equipe de pesquisa.

Utilizou-se, como instrumento da pesquisa, o questionário semiestruturado. Optou-se por esse modelo pelo fato de, ao mesmo tempo, conseguir captar de forma eficiente as informações desejadas, bem como abrir espaço para que o interlocutor possa espontaneamente manifestar-se. Seguem abaixo os dados das empresas pesquisadas do APL de Confecção de Catalão.

Das pessoas que responderam a pesquisa, a maior parte encontrava-se em função de liderança, somados $92 \%$, dos quais $69 \%$ são os próprios empresários, $15 \%$ os administradores e $8 \%$ gerentes administrativos. Quase a metade dos entrevistados (46\%) possui Ensino Médio e apenas $23 \%$ possui curso superior. Entre as empresas pesquisadas, $24 \%$ dizem não participar do Setor de Indústria. Considerando que a amostra foi composta, em sua totalidade, de confeccionistas, ou seja, fabricantes, a pesquisa nos mostra que algumas empresas deixaram de fabricar e passaram apenas a comercializar os produtos de outras confecções, no caso, os $24 \%$ que disseram não fabricar.

A segmentação da produção das confecções da cidade é bem distribuída: $30 \%$ produzem roupas profissionais, $30 \%$ peças de vestuário (exceto roupas íntimas), 35\% roupas 
íntimas e 5\% de malharias e tricotagens (exceto meias), ver gráfico 1. A maioria das empresas (81\%) enquadra-se como microempresas, ou seja, possui até 19 funcionários, considerando se tratar do segmento de indústria. Mais da metade dos entrevistados diz participar do setor de comércio, 52\%. Dentro dessa amostra (52\%) há empresas que apenas comercializam os produtos de outras fábricas, correspondendo $24 \%$, apresentados no parágrafo anterior. O restante $(28 \%)$ fabricam e comercializam seus próprios produtos em loja própria.

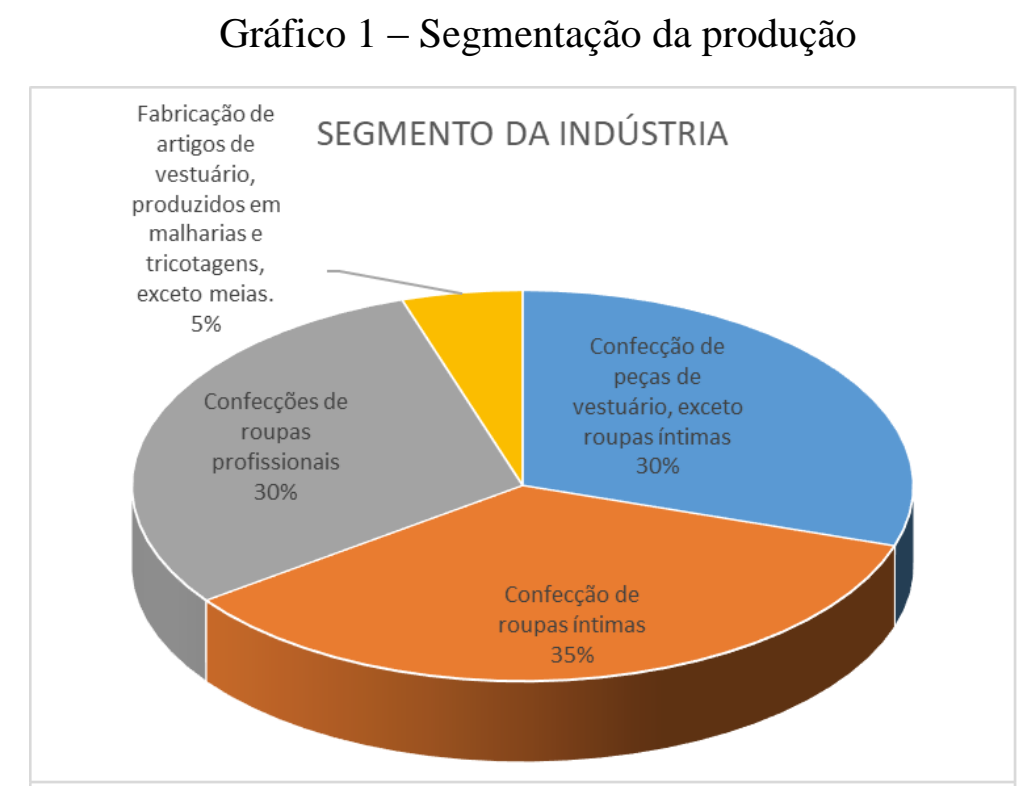

Fonte: elaborado pela equipe de pesquisa.

A maioria das empresas (62\%) têm mais de dez anos de abertura, ver gráfico 2, um dado importante, visto que grande parte das micro e pequenas empresas fecham as suas portas antes dos 5 anos de funcionamento. A maioria das empresas pesquisadas (57\%) trabalha com 1 a 5 funcionários e trabalham com a mesma quantidade de funcionários terceirizados (62\%). 


\section{Gráfico 2 - Tempo de Abertura da Empresa}

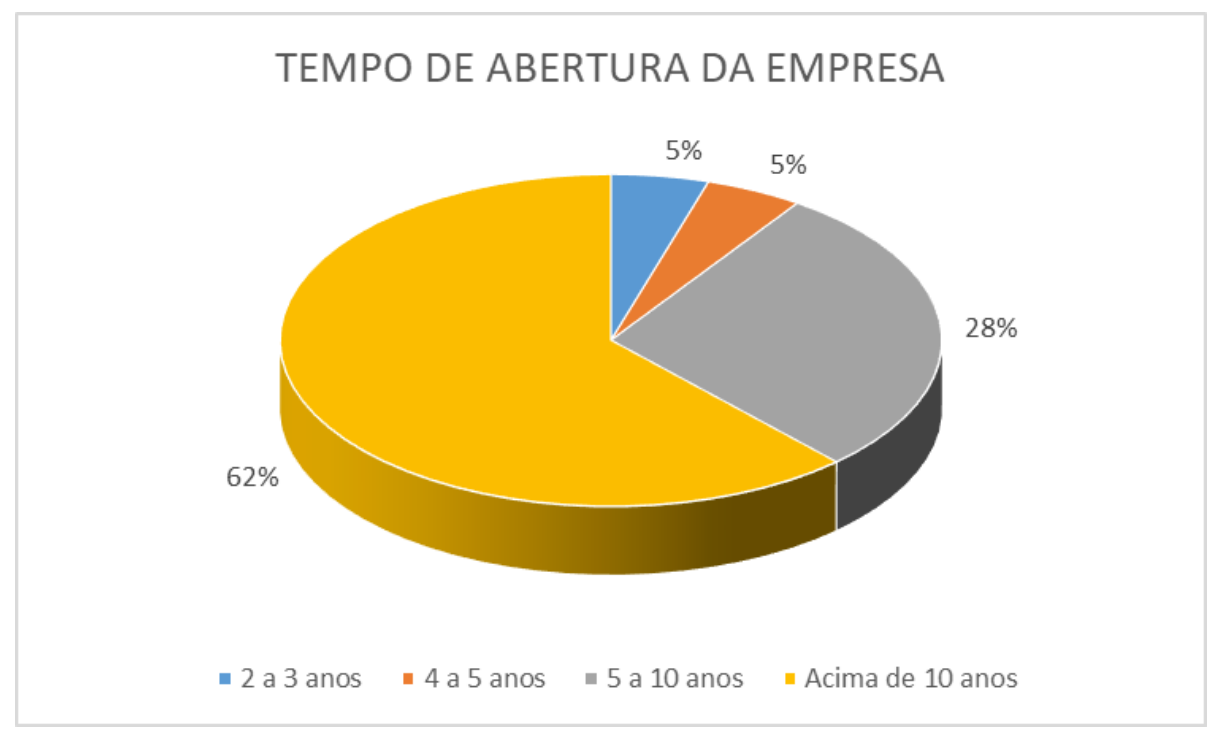

Fonte: elaborado pela equipe de pesquisa.

Quando questionados em relação à participação no APL de Confecção, 86\% dos empresários afirmam não participar do referido arranjo produtivo local, mesmo estando registrados como tal na Secretaria de Estado de Desenvolvimento Econômico, Científico e Tecnológico e de Agricultura, Pecuária e Irrigação - SED. Por não ter consciência da participação no APL, não utilizam dos benefícios do mesmo, como participar de um grupo de compras por exemplo.

No caso de Catalão, para beneficiar o APL de Confecção, o Governo do Estado de Goiás disponibilizou uma máquina para a digitalização, enfesto e corte de tecidos chamada Audaces. A máquina em questão permite maior corte de peças de uma só vez, reduzindo o tempo gasto neste processo, além de minimizar os erros e desperdícios causados por cortes errados, ou seja, otimiza os processos e aumenta a produtividade. No entanto, mesmo a aplicação desta política pública, o APL não é beneficiado. Principalmente porque eles não se percebem como APL, como mostrado na questão anterior.

Em relação ao suprimento da produção, a esmagadora maioria dos fornecedores do APL de Confecções de Catalão são de Goiânia, município conhecido atualmente como um dos principais pontos de fornecimento de tecidos. Ainda sobre o fornecimento, é representativo o fato de que um terço (33\%) dos fabricantes diz nunca procurar novos fornecedores. Também impressiona o fato que $29 \%$ dos confeccionistas afirma nunca pesquisar por novas matérias primas. Mantendo a mesma perspectiva, 19\% dos entrevistados disse não substituir os fornecedores e/ou produtos em um tempo menor do que cinco anos. 
O lançamento de novas coleções não obedece a um calendário muito rígido, conforme demonstra o gráfico 3. As confecções também oferecem pouca variedade de modelos, $48 \%$ lança, no máximo, 10 modelos por coleção. No entanto, oferecem quantidade, $43 \%$ das confecções produzem acima de 50 peças por modelo. Das empresas pesquisadas, $80 \%$ possuem capacidade de produção atual de 5.000 peças ao mês. E o tempo gasto para o desenvolvimento de um produto é de um mês para $86 \%$ das empresas.

Gráfico 3 - Frequência de Lançamento de Novas Coleções

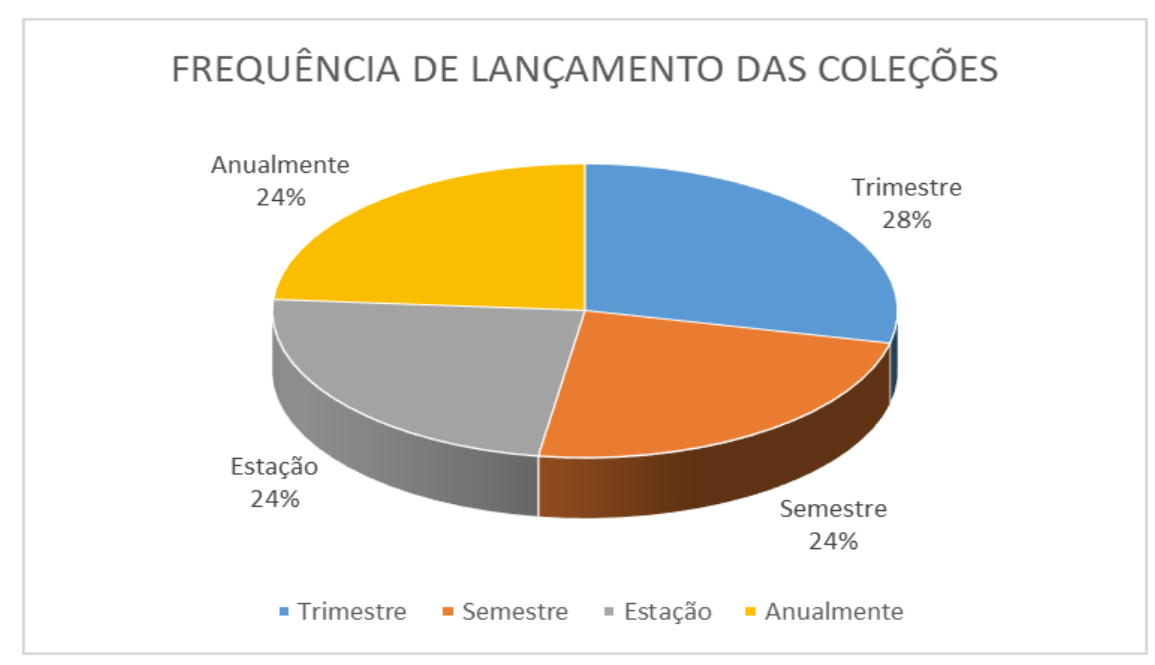

Fonte: elaborado pela equipe de pesquisa.

Com relação aos clientes, todos os entrevistados consideram as opiniões deles válidas, e disseram ter estrutura para personalização dos produtos de acordo com a demanda dos compradores. O que é importante, principalmente nos dias atuais, onde boa fatia do mercado busca produtos personalizados.

No processo produtivo, boa parte ainda é realizada de forma manual, como é o caso do enfesto (95\%), encaixe do molde (90\%) e do procedimento de riscar as peças (90\%). Em $95 \%$ dos casos, o corte ocorre com máquina de corte circular. Em relação à utilização da estrutura existente, $43 \%$ afirmaram ter gerado renda a partir da mesma, sob as mais variadas formas, $43 \%$ as empresas conseguiram gerar renda a partir de novos produtos e/ou serviços.

Dentre os entrevistados, $62 \%$ dizem ter os processos definidos, seguidos por $24 \%$ que não possuem e $14 \%$ que dizem possuir os processos definidos em parte. Com relação aos controles organizacionais, a amostra aponta uma deficiência importante, $71 \%$ não utiliza nenhum software para ajudar em sua gestão, mesmo nos dias atuais onde a tecnologia está muito presente. A estratégia organizacional é outro ponto pouco trabalhado, como mostra o gráfico 4. 


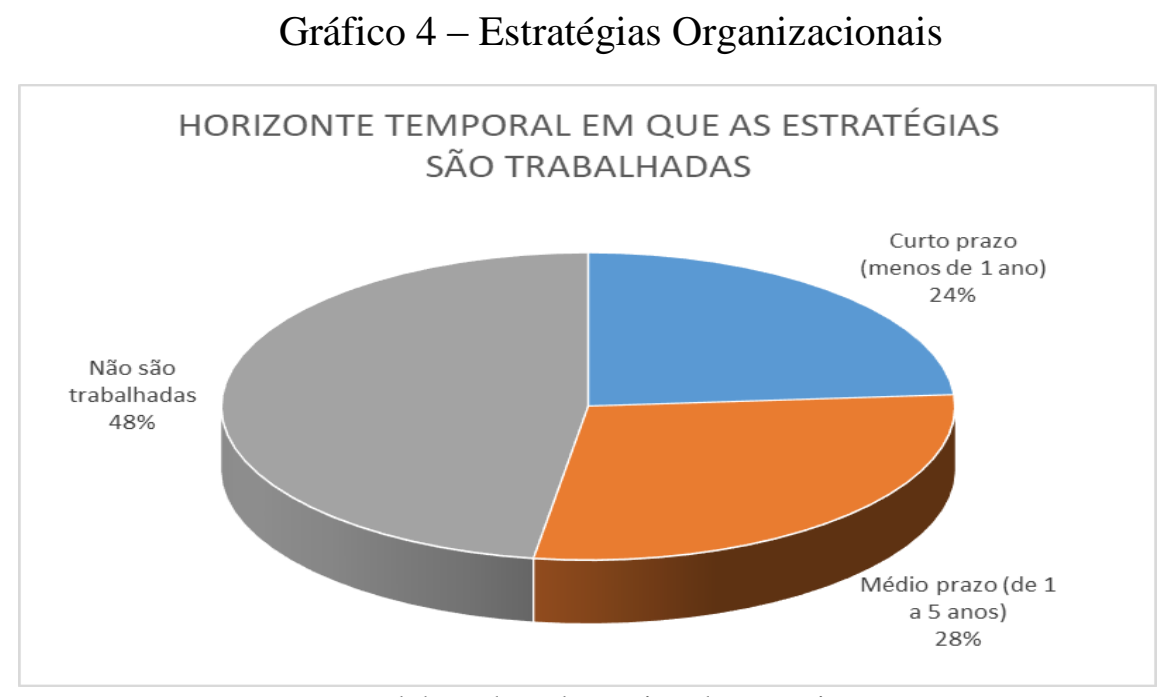

Fonte: elaborado pela equipe de pesquisa.

A maioria absoluta, $90 \%$, possui uma marca definida em suas confecções, que é bem explorada em variadas formas, desde embalagens (17\%), passando por etiquetas (35\%), até em publicações na internet (28\%). Apesar da marca ser amplamente divulgada em materiais, $71 \%$ não as registrou. Com relação ao público alvo, quase a metade das empresas (43\%) direciona seus produtos para o público feminino. Para tanto utilizam como principal forma de comunicação com o cliente o aplicativo de comunicação WhatsApp (44\%), seguido das ligações telefônicas.

Apesar de se fazerem presentes de alguma forma na internet, $81 \%$ não possibilita vendas diretas por meio da rede. No que tange à divulgação, 76\% apresentam suas marcas nas redes sociais. O Facebook (57\%) e o Instagram (39\%) são as redes sociais mais utilizadas. No quesito distribuição. As confecções exploram as vendas a varejo, em lojas físicas ou virtuais (32\%), no atacado (39\%), $18 \%$ de vendas diretas.

Quadro 2 - Cursos apontados na pesquisa

\begin{tabular}{|l|r|}
\hline Administração financeira & $17 \%$ \\
\hline Atendimento ao cliente & $9 \%$ \\
\hline Bordados & $9 \%$ \\
\hline Cálculo de custos de produção & $8 \%$ \\
\hline Consultoria na área de produção & $8 \%$ \\
\hline Costura industrial e modinha & $8 \%$ \\
\hline Cursos técnicos na área de costura & $17 \%$ \\
\hline Formação de preço e venda & $8 \%$ \\
\hline Gestão & $8 \%$ \\
\hline Serigrafia &
\end{tabular}

Fonte: elaborado pela equipe de pesquisa. 
Mediante as informações obtidas na pesquisa, incluindo os apontamentos de cursos do quadro 2, foi elaborado sugestões para aplicação no APL de Confecção de Catalão que se segue:

Trabalhar o fortalecimento do APL de confecção por meio da divulgação do seu conceito e das vantagens oferecidas aos seus participantes. Promover uma feira, juntamente com desfile de modas, utilizando o espaço do ITEGO Labibe Faiad, com o objetivo de aproximar as confecções, proporcionar a interação entre a comunidade e a rede ITEGO, criando oportunidades de vendas e, consequentemente, fortalecimento do APL.

Oferecer orientações e curso in company às confecções. Criar um banco de talentos composto pelos alunos do ITEGO Prof. Antônio Salles para que os empresários possam buscar pessoas capacitadas para trabalhar em suas confecções dentro da própria instituição. Criar um grupo de compras com os empresários participantes do APL para que possam comprar em grandes quantidades e conseguir melhores preços para a matéria prima e os insumos de produção.

Incentivar as confecções a fazerem os cortes dos tecidos na máquina Audaces por meio da apresentação do equipamento e auxilio para o planejamento da produção. Ofertar novos cursos de gestão e técnicas de costura no ITEGO Prof. Antônio Salles. Ofertar cursos de gestão das redes sociais e e-comerce como alternativas para aumentar o faturamento das confecções.

\section{CONSIDERAÇÕES FINAIS}

A partir do acima descrito, percebem-se várias carências no campo da gestão das empresas. Aparentemente, os empresários souberam conduzir suas confecções durante o período áureo que a economia do país vivenciou há cerca de dez anos. Com a crise financeira que acometeu o Brasil, os confeccionistas sofreram bastante com a diminuição do volume de negócios e continuam sofrendo ainda as consequências desse contexto. No entanto, mesmo diante das drásticas mudanças na macroeconomia brasileira, os gestores das empresas investigadas não procuraram melhorar os processos ou implementar novas formas de gestão, como tampouco os produtos, os fornecedores e as matérias primas.

A pesquisa revela ainda que a quantidade de funcionários das próprias fábricas caiu muito em relação ao período 2012-2018. Segundo documento da Gerência de Arranjos Produtivos Locais, o APL em questão contava em 2012 com aproximadamente 1000 trabalhadores formais diretos e a mesma quantidade de indiretos. De lá para cá, segundo esta pesquisa, o número atual gira em torno de 192 trabalhadores formais diretos e 115 indiretos.

Rev. de Direito, Inovação, Propriedade Intelectual e Concorrência| e-ISSN: 2526-0014 | Porto Alegre | v. 4 | n. 2 |p. 96-113| Jul/Dez. 2018 
As informações obtidas na pesquisa mostram desaceleração econômica do segmento e uma forte desarticulação do APL de confecção. Uma APL que foi articulado no ano de 2012 e que seis anos depois, os próprios confeccionistas não se percebem mais pertencentes a um grupo. Percebeu-se na aplicação da pesquisa que eles se vêm mais como concorrentes do que como parceiros que podem crescer juntos, unindo forças, interagindo entre si.

Com o diagnóstico realizado e a partir das sugestões apresentadas para o fortalecimento do APL de Confecção de Catalão, várias políticas públicas podem ser elaboradas e executadas de forma mais assertivas, solucionando problemas reais e urgentes, evitando assim, gastos desnecessários com políticas públicas que não atendem à necessidade local. Também se desdobrou deste trabalho várias sugestões de ações que podem ser implementadas pela OS Instituto Reger nas empresas do APL, permitindo ao mesmo cumprir suas metas, alcanças seus indicadores, cumprindo assim o contrato de gestão firmado com o Estado.

De tudo, a sociedade de Catalão é a mais beneficiada, pois, proporcionando a interiorização das políticas públicas, por meio do contrato de gestão firmado entre a OS e o Estado, percebe-se que é possível incentivar o crescimento e o desenvolvimento da economia local.

\section{REFERÊNCIAS BIBLIOGRÁFICAS}

BRASIL. Presidência da República. Plano diretor da reforma do aparelho de estado. Brasília: Presidência da República, Câmara da reforma do Estado, Ministério da Administração e da Reforma do Estado, 1995.

BRASIL. Ministério da Administração Federal e Reforma do Estado. Organizações sociais. Brasília, 1997. (Cadernos MARE da Reforma do Estado).

BRESSER-PEREIRA, Luiz C. Reforma gerencial e legitimação do estado social. Revista de Administração Pública. Rio de Janeiro 51(1):147-156, jan. - fev. 2017

BUCCI, Maria P. D. Direito Administrativo e Políticas Públicas. São Paulo: Saraiva, 2002.

FERNANDES, Rubens C. Privado Porém Público: O terceiro Setor na América Latina. 2. ed. Rio de Janeiro: Relume - Dumaré, 1994.

GOIÁS. Lei n. 15.503 de 28 de dezembro de 2005. Dispõe sobre a qualificação de entidades como organizações sociais estaduais, disciplina o procedimento de chamamento e seleção 
públicos e dá outras providências. Diário Oficial [do Estado de Goiás], Goiânia, GO, 09 jan. 2006.

GOIÁS. Resolução Normativa n. 13 de 01 de dezembro de 2017. Dispõe sobre a fiscalização da qualificação de entidades como organizações sociais, da formalização e da execução dos contratos de gestão firmados pelo Estado de Goiás, e regulamenta as prestações de contas anuais a serem disponibilizadas aos órgãos ou entidades supervisoras e dá outras providências. Tribunal de Contas [do Estado de Goiás], Goiânia, GO, 13 dez. 2017.

GOIÁS. Decreto n 5.990, de 12 de agosto de 2004. Institui a Rede Goiana de Apoio a Arranjos Produtivos Locais e dá outras providências. Diário Oficial [do Estado de Goiás], Goiânia, GO, 12 ago. 2004.

SED - Secretaria de Estado de Desenvolvimento Econômico, Científico e Tecnológico e de Agricultura, Pecuária e Irrigação. OS Transparência - Regionais. Goiânia, 2017. Disponível em: <http://www.sed.go.gov.br/post/ver/225285/transparencia---regionais>. Acesso em: 01 de ago. 2018.

SED - Secretaria de Estado de Desenvolvimento Econômico, Científico e Tecnológico e de Agricultura, Pecuária e Irrigação. EDITAL CHAMAMENTO PÚBLICO Nº07/2016-SED. Goiânia, 2016. Disponível em: <https://www.institutoreger.org.br/wpcontent/uploads/2017/11/CHAMAMENTO-07.2016.pdf>. Acesso em: 08 de mai. 2018.

TAVARES NETO, J. Q.; FERNANDES, A. O. F. Terceiro setor e interesses coletivos: as alternativas sociais na busca da cidadania. Revista Sequência, n. 60, p. 371-390, jul. 2010.

UFG, Universidade Estadual de Goiás. Programa de Pós-Graduação em Direito e Políticas Públicas - PPGDP. Goiânia, 2018. Disponível em: < https://ppgdp.direito.ufg.br/>. Acesso em: 08 de set. 2018. 